\title{
The Effect of Home Confinement During COVID-19 on Stress and Eating Disorders in Saudi Arabia
}

\section{Khloud Ghafouri ${ }^{1 *}$, Jameelah Alqarni ${ }^{1}$, Wedad Azhar ${ }^{1}$, Hibah Almasmoum $^{2}$ and Alaa Qadhi ${ }^{1}$}

${ }^{1}$ Clinical Nutrition, Umm AL-Qura University, Saudi Arabia

${ }^{2}$ Laboratory Medicine, Umm AL-Qura University, Saudi Arabia

*Corresponding Author: Khloud Ghafouri, Clinical Nutrition, Umm AL-Qura

University, Saudi Arabia.
Received: September 17, 2021

Published: September 29, 2021

(C) All rights are reserved by Khloud

Ghafouri., et al.

\begin{abstract}
Background: Home confinement during the COVID-19 pandemic drastically affected the daily lives of millions of people around the world. It created a situation across the globe that is expected to affect human mental and physical health in different ways. For instance, it might increase the prevalence of eating disorders (EDs), a common health problem affecting both genders. The incidence of EDs during home confinement may be affected by stress and high exposure to social media.

Objective: To investigate the incidence of developing EDs among the Saudi population during the COVID-19 pandemic. In particular, this study seeks to analyse the effect of stress and exposure to social media on the development of EDs.

Methods: A cross-sectional study was undertaken from April 272020 to June 15 2020. A total of 1,867 adult residents of Saudi Arabia aged between 18-80 participated in this study, completing a self-reported questionnaire. A SCOFF questionnaire was used for ED screening, while the Perceived Stress Scale (PSS) was used for measuring stress levels. Data were analysed using SPSS statistical software. Descriptive statistics were used to identify the demographic characteristics of the participants.

Results: Of the 1867 participants, 39.9\% gave a positive SCOFF score. Approximately 40.9\% of participants reported an increase in body weight during the quarantine. Most of them (80.8\%) had a perception about ideal body shape, and more than half (58\%) reported they thought about their figure more during the quarantine. A significant relationship has been noticed between the development of EDs and age (P-Value: 0.019), job (P-Value: 0.001), having a health condition that requires medication (P-Value: 0.021), being a smoker (P-Value: 0.001), and spending time on social media (P-Value: 0.001). Additionally, the level of stress (P-Value: 0.001), working from home during the home confinement (P-Value: 0.044), and the impact of the home confinement on monthly income (PValue: 0.004 ) were found to have a significant relationship with having a positive screening for EDs.
\end{abstract}

Keywords: Mental Health; Underweight; Obesity; Anorexia; Bulimia; COVID-19

\section{Abbreviations}

DSM-5: Diagnostic and Statistical Manual of Mental Disorders $-5^{\text {th }}$ edition; EDs: Eating Disorders; AN: Anorexia Nervosa; BN: Bulimia Nervosa; BED: Binge Eating Disorders; COVID-19: Corona Vi- rus Disease 2019; TV: TeleVision; PSS: Perceived Stress Scale; SPSS: Statistical Package for the Social Sciences; BMI: Body Mass Index; SES: Socio-economic Status. 


\section{Introduction}

According to the Diagnostic and Statistical Manual of Mental Disorders $-5^{\text {th }}$ edition (DSM-5), there are three common eating disorders (EDs): anorexia nervosa, bulimia nervosa and binge eating disorders (BED) [1,2]. Anorexia nervosa (AN) is characterised by self-starvation, whereby people voluntarily eat too little due to a morbid fear of gaining weight [3]. AN sufferers see themselves as overweight, even when they are emaciated [3]. Contrastingly, bulimia nervosa is characterised by repeated binge eating followed by intense weight-control behaviours, such as prolonged fasting, selfinduced vomiting and laxative and diuretic maluses [4].

A range of risk factors may also contribute to the likelihood of the development of EDs, such as increased time spent on social media and the harmful effects of ideal body shape objectification [5]. Isolation and loneliness are typical consequences of anorexia nervosa (AN) and may be exacerbated by forced quarantine. Problems with regulating emotions can lead to EDs symptoms [6], while food intake can be decreased as a consequence of increased external control [7]. Media exposure appears to have an effect on increasing body dissatisfaction, eating disorders and causing thinness. This effect is greater when we look at media that present thinness as an ideal for which to strive [8]. Those people with high levels of initial body image dissatisfaction or constrained eating tend to experience more pronounced media exposure effects [8].

Media tend to be held responsible for the increased occurrence of EDs on the grounds that they transmit images of idealised slimness and fitness that motivate or even force people to try and achieve thinness themselves [9]. The media are blamed for misrepresenting the models and celebrities that they feature by either depicting them as naturally thin or glamorising those who are unnaturally thin. Tiggemann and Pickering (1996) discovered that body image dissatisfaction and idealised thinness among girls are linked to increased exposure to certain types of TV shows [10].

Additionally, stress and anxiety may play a critical role in the development of EDs [11]. The current COVID-19 pandemic has drastically affected the daily lives of millions of people around the world [12]. The concept of home confinement is novel for the general public and has influenced myriad social, economic and psychological aspects of our lives [12]. The health crisis has created a situation across the globe that is likely to increase the risk and symptoms of EDs $[3,13]$. Concerns about health and fitness during confinement might serve as a precipitating factor for the development of EDs in vulnerable individuals [13].

In a pilot study carried out at the EDs Unit of the Department of Psychiatry at the University Hospital of Bellvitge (Barcelona, Spain), researchers used a survey to monitor the impact of the first two weeks of confinement, revealing that most ED patients presented worries about increased uncertainties in their lives, such as the risk of COVID-19 infection for themselves or their loved ones, the negative impact on their work and their treatment. Almost 38\% reported worsen of their ED symptomatology, and 56.2\% reported additional anxiety symptoms. Among the sample of participants, four patients reported that stress was making it difficult for them to control their grazing behaviour and emotional eating [13].

A link between COVID-19 and the development of EDs has been established in Spain, but it remains unclear whether the same effect of domestic confinement on the development of EDs is present among the Saudi population. Therefore, this study aims to screen the incidence of developing EDs among the Saudi population during the COVID-19 pandemic and investigate the effect of pandemicrelated stress on EDs.

\section{Materials and Methods \\ Study design and sampling}

A descriptive, cross-sectional survey was conducted online from April 27 to June 15 2020. A bilingual (Arabic and English), self-administered questionnaire was distributed to Saudi adults aged 18-80 years who reside in Saudi Arabia. The questionnaire was distributed via social media (WhatsApp, Facebook and Twitter).

The first page of the questionnaire was an informed consent form. Following this, the body of the questionnaire composed of four sections. The first section dealt with demographic characteristics, including gender, age, nationality, marital status, city residence, smoking habits before and during domestic confinement, health status and physical activity level. The second section surveyed eating habits, particularly binge eating and social media exposure, the time of day of increased food consumption, time spent watching TV and using social media participants' perceptions of ideal body shape and physical activity during the day and 
the amount of time spent doing the physical activity each day. The third section inquired about ED screening using the SCOFF questionnaire, including five items addressing the main features of EDs. One point was awarded for every 'yes', and a score of $>=2$ indicates a likely case of EDs. The scale has been validated and demonstrates effective specificity in identifying EDs. The fourth section focused on measuring stress using the Perceived Stress Scale (PSS). Participants were asked to report on their experienced stress levels from every day in the previous month. Responses were given on a five-point scale ranging from 'never' to 'very often'. The study was approved by the Biomedical Ethical Committee of Umm Al-Qura University, Saudi Arabia (HAPO-02-K-012-2020-06-397).

\section{Statistical analyses}

All collected data were verified manually. The data were coded before their entry into a spreadsheet in Excel Version 2016 (Microsoft Corp., Redmond, Washington, USA). All data were analysed using the Statistical Package for the Social Sciences (SPSS) (IBM SPSS Statistics for Windows, Version 23.0. Armonk, NY: IBM Corp). All descriptive statistics were presented regarding the participants' socio-demographic characteristics (i.e. age, gender, marital status, education level, household register, occupation, monthly household income and weight difference before and after quarantine). Descriptive statistics were calculated for all variables; quantitative variables were presented as mean (SD), while categorical variables were used for frequency and percentage. A chi-squared test was used to test for a relationship between categorical variables. When small cell size (expected values less than 5) resulted, a Fisher's exact test was performed. A P-value $\leq 0.05$ was regarded as statistically significant.

\section{Results and Discussion}

In total, 1,867 (1,329 female and 538 male) participants were recruited from all regions in Saudi Arabia. The socio-demographic characteristics of the participants are shown in table 1 below.

\begin{tabular}{|l|c|}
\hline Demographic Characteristics & n (\%) \\
\hline Age & \\
\hline $18-24$ & $432(23.10 \%)$ \\
\hline $25-34$ & $490(26.20 \%)$ \\
\hline $35-44$ & $502(26.90 \%)$ \\
\hline $45-54$ & $288(15.40 \%)$ \\
\hline $55-64$ & $133(7.10 \%)$ \\
\hline
\end{tabular}

\begin{tabular}{|c|c|}
\hline $65-74$ & $21(1.10 \%)$ \\
\hline$\geq 75$ & $1(0.10 \%)$ \\
\hline \multicolumn{2}{|l|}{ Marital Status } \\
\hline Single & $593(31.80 \%)$ \\
\hline Engaged & $43(2.30 \%)$ \\
\hline Married & $1094(58.60 \%)$ \\
\hline Widowed & $25(1.30 \%)$ \\
\hline Divorced & $98(5.20 \%)$ \\
\hline Separated & $14(0.70 \%)$ \\
\hline \multicolumn{2}{|l|}{ Education } \\
\hline Non & $25(1.30 \%)$ \\
\hline High School & $350(18.70 \%)$ \\
\hline Diploma & $145(7.80 \%)$ \\
\hline Bachelor & $1057(56.60 \%)$ \\
\hline Master & $186(10.00 \%)$ \\
\hline $\mathrm{PhD}$ & $104(5.60 \%)$ \\
\hline \multicolumn{2}{|l|}{ Occupation } \\
\hline Work in public sector & $546(29.20 \%)$ \\
\hline Work in private sector & $252(13.50 \%)$ \\
\hline Self-employed & $51(2.70 \%)$ \\
\hline Not working and looking for a job & $210(11.20 \%)$ \\
\hline $\begin{array}{l}\text { Not working and not looking for } \\
\text { job }\end{array}$ & $62(3.30 \%)$ \\
\hline Housewife & $234(12.50 \%)$ \\
\hline Student & $333(17.80 \%)$ \\
\hline Military & $18(1.00 \%)$ \\
\hline Physician & $41(2.20 \%)$ \\
\hline Retired & $113(6.10 \%)$ \\
\hline Unable to work & $7(0.40 \%)$ \\
\hline \multicolumn{2}{|l|}{ Monthly Income/SAR } \\
\hline$<2,000$ & $635(34.00 \%)$ \\
\hline $2,000-3,500$ & $187(10.00 \%)$ \\
\hline $3,600-4,500$ & $81(4.30 \%)$ \\
\hline $5,000-10,000$ & $305(16.30 \%)$ \\
\hline $12,000-20,000$ & $489(26.20 \%)$ \\
\hline $20,000-25,000$ & $110(5.90 \%)$ \\
\hline$>30,000$ & $60(3.20 \%)$ \\
\hline
\end{tabular}

Table 1: Socio-demographic profile of the participants $(n=1867)$. 
The mean number of family members living in the same house as the participants was $5.77 \pm 2.40$ (minimum 2 and maximum 17). In figure 1 the number of people in the house is presented as following, more than half of the participants were living with children, about 886 (47.5\%) were living with a spouse, 511 (27\%) were living with both parents, 155 (8.8\%) were living with one parent, 485 (26\%) were living with a sibling(s), 445 (23\%) were living with a housekeeper, 86 (4.6\%) were living with a grandparent(s), and only $53(2.8 \%)$ reported living alone.

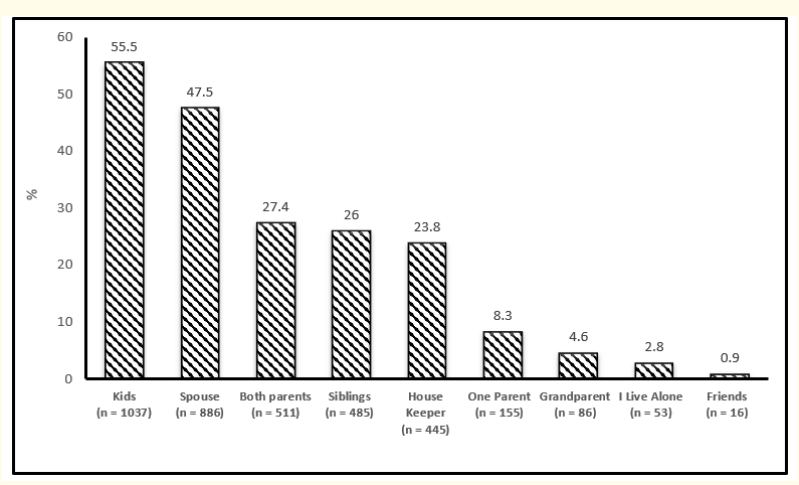

Figure 1: Number of people in the household.

\section{Working during COVID-19}

Figure 2 illustrates the effect of COVID-19 on the nature and location of work. About 1,064 (62.4\%) participants reported not working from home during the quarantine, 552 (37\%) reported working from home during the quarantine, and 251 (13.4\%) worked from home in shifts.

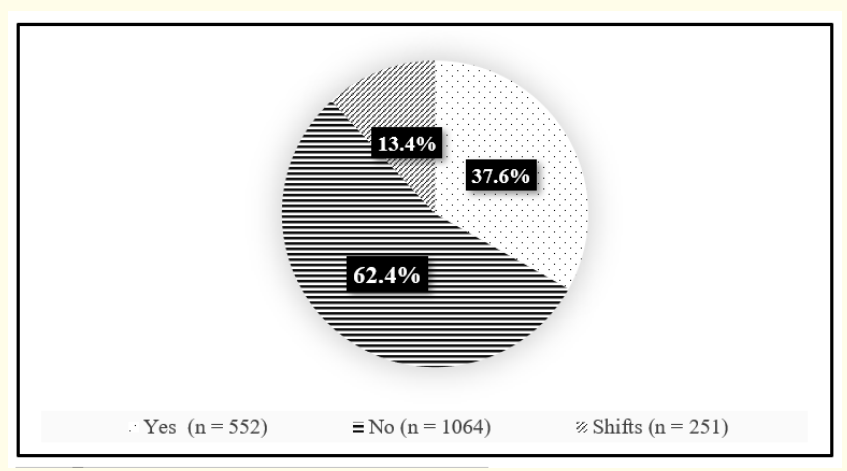

Figure 2: Effect of COVID-19 on nature and location of work.
A majority of 1271 (68.1\%) of the participants reported no change in their monthly income due to the quarantine. Another $469(25.1 \%)$ respondents saw a decrease in their monthly income, with only $127(6.8 \%)$ reporting an increase in their monthly income.

A majority of 1379 (73.9\%) participants did not have any health condition that required treatment with medication. Another 488 (26.1\%) participants were consuming medication to treat health issues such as diabetes mellitus type-1 12 (0.6\%), diabetes mellitus type-2 37 (2\%), hypertension 44 (2.4\%), cardiovascular disease $20(1.1 \%)$ and gastrointestinal disease 72 (3.9\%). A vast majority of 1534 (82\%) of the sample were non-smokers, whereas $255(13.7 \%)$ were smokers, and 78 (4.2\%) smoked occasionally. In addition, $515(27.2 \%)$ participants reported cohabiting with a smoker(s) who smoked an average of one to more than 15 cigarettes a day, and 1352 (72.5\%) did not share a living space with a smoker. Around 138 (7.4\%) participants noted a change in their smoking habits during the quarantine, with 64 (3.4\%) reporting a single increase, 60 (3.2\%) reporting a double increase, $12(0.6 \%)$ reporting a triple increase and $4(0.2 \%)$ reporting a four-fold increase in their cigarette consumption.

Body weight and perception during domestic confinement

Table 2 shows participants' BMI and weight. One hundred and thirty (7\%) participants were underweight, 619 (33.2\%) had normal weight, 565 (30.3\%) were overweight, 347 (18.6\%) were class I obese, 137 (7.3\%) were class II obese, and 69 (3.7\%) were class III obese. About 763 (40.9\%) participants reported their weight increasing during the quarantine, while 1,104 of the participants did not note any change in their body weight during the quarantine. The majority of the participants ate while watching TV or other streaming devices, either 'usually' (38.6\%) or 'sometimes' (36.2\%). The remaining $25 \%$ did not eat while watching TV or other streaming devices.

Regarding the perception of body image during the quarantine, $1,083(58 \%)$ reported thinking about body figure more during the quarantine, while 333 (17.8\%) participants reported not thinking more about it. A majority of 1,508 (80.8\%) participants described having a perception of ideal body shape, and only $19.2 \%$ of the participants reported not having such a perception. The question about ideal body shape yielded the following responses: $0.7 \%$ for very skinny, $41.2 \%$ for thin, $16.2 \%$ for buxom, and $20.7 \%$ for mus- 


\begin{tabular}{|c|c|}
\hline Question & n (\%) \\
\hline \multicolumn{2}{|c|}{ BMI and Weight During the Quarantine } \\
\hline \multicolumn{2}{|l|}{ BMI Classes } \\
\hline Underweight & $130(7 \%)$ \\
\hline Normal & $619(33.2 \%)$ \\
\hline Overweight & $565(30.3 \%)$ \\
\hline Class I Obesity & $347(18.6 \%)$ \\
\hline Class II Obesity & $137(7.3 \%)$ \\
\hline Class II Obesity & $69(3.7 \%)$ \\
\hline \multicolumn{2}{|c|}{ Weight Gain During COVID-19 Domestic Confinement } \\
\hline Yes & $763(40.9 \%)$ \\
\hline No & $1,104(59.1 \%)$ \\
\hline \multicolumn{2}{|c|}{ Do you eat while watching TV or other streaming devices? } \\
\hline Yes & $721(38.6 \%)$ \\
\hline No & $471(25.2 \%)$ \\
\hline Sometimes & $675(36.2 \%)$ \\
\hline \multicolumn{2}{|c|}{ Perception Toward Body During The Quarantine } \\
\hline \multicolumn{2}{|c|}{$\begin{array}{l}\text { Do you think about your figure more often during the } \\
\text { quarantine? }\end{array}$} \\
\hline Yes & $1,083(58 \%)$ \\
\hline No & $333(17.8 \%)$ \\
\hline Sometimes & $451(24.2 \%)$ \\
\hline \multicolumn{2}{|c|}{ Do you have a perception of ideal body shape? } \\
\hline Yes & $1,509(80.8 \%)$ \\
\hline No & $358(19.2 \%)$ \\
\hline \multicolumn{2}{|c|}{ What is the ideal body shape, in your opinion? } \\
\hline Very skinny & $14(0.7 \%)$ \\
\hline Thin & $770(41.2 \%)$ \\
\hline Buxom & $302(16.2 \%)$ \\
\hline Muscly & $386(20.7 \%)$ \\
\hline There is no perfect body shape & $395(21.2 \%)$ \\
\hline \multicolumn{2}{|l|}{ How do you see your body shape? } \\
\hline Very skinny & $52(2.8 \%)$ \\
\hline Thin & $363(19.4 \%)$ \\
\hline Buxom & $903(48.4 \%)$ \\
\hline Muscly & $67(3.6 \%)$ \\
\hline Out of shape & $482(25.8 \%)$ \\
\hline \multicolumn{2}{|l|}{ Exercising During the Quarantine } \\
\hline
\end{tabular}

\begin{tabular}{|c|c|}
\hline \multicolumn{2}{|c|}{ Do you exercise during the quarantine? } \\
\hline Yes & $924(49.5 \%)$ \\
\hline No & $943(50.5 \%)$ \\
\hline \multicolumn{2}{|c|}{ If you are exercising, how long do you spend exercising a day? } \\
\hline Half an hour & $529(28.3 \%)$ \\
\hline An hour & $307(16.4 \%)$ \\
\hline Two hours & $61(3.3 \%)$ \\
\hline Three hours & $15(0.8 \%)$ \\
\hline Four hours & $6(0.3 \%)$ \\
\hline 5 hours or more & $1(0.1 \%)$ \\
\hline \multicolumn{2}{|c|}{ Social Media Usage During the Quarantine } \\
\hline \multicolumn{2}{|c|}{$\begin{array}{l}\text { Do you spend time on social media like Instagram, TikTok, } \\
\text { Snapchat, YouTube or Twitter? }\end{array}$} \\
\hline Yes & $1,370(73.4 \%)$ \\
\hline No & $89(4.8 \%)$ \\
\hline Occasionally & $408(21.9 \%)$ \\
\hline \multicolumn{2}{|c|}{ If you use social media, how long do you spend on it a day? } \\
\hline Half an hour & $86(4.6 \%)$ \\
\hline An hour & $198(10.6 \%)$ \\
\hline Two hours & $343(18.4 \%)$ \\
\hline Three hours & $335(17.9 \%)$ \\
\hline Four hours & $254(13.6 \%)$ \\
\hline 5 hours and more & $561(30 \%)$ \\
\hline
\end{tabular}

Table 2: BMI and Weight During the Quarantine ( $\mathrm{N}=1867)$.

cly, while $21.2 \%$ thought that there is no such thing as a perfect body shape. Nine hundred and three $(48.4 \%)$ of the participants saw their body shape are buxom, $482(25.8 \%)$ reported themselves as out of shape, $363(19.4 \%)$ described themselves as thin, and 67 (3.6\%) described themselves as muscly. Only 52 (2.8\%) perceived themselves to be very skinny.

Nine hundred and twenty-four (49.5\%) participants reported taking regular exercise, while 943 (50.5\%) reported not taking exercise. The participants who exercised reported variations in the amount of time spent doing physical activity, ranging from the 529 (28\%) who take half of an hour to the one $(0.1 \%)$ who take five hours and more. The percentages of individuals reporting exercising for an hour, two hours, three hours and four hours were 307 (16.4\%), $61(3.3 \%), 15(0.8 \%)$ and $6(0.3 \%)$, respectively.

Citation: Khloud Ghafouri., et al. "The Effect of Home Confinement During COVID-19 on Stress and Eating Disorders in Saudi Arabia". Acta Scientific Nutritional Health 5.10 (2021): 106-117. 
One thousand three hundred and seventy (73.4\%) of the participants reported that they always spend time on social media platforms like Instagram, TikTok, Snapchat, YouTube or Twitter. Four hundred and eight (21.9\%) occasionally spent time on social media, and 89 (4.8\%) reported spending no time. The time spent on social media varied from 30 minutes a day to more than five hours a day among participants.

Table 3 shows the factors associated with having an abnormal BMI. The results indicate that perception about ideal body shape had significant effects on being underweight $(\mathrm{P}<0.001)$. Opinions regarding the ideal body shape appear to be significantly correlated with being underweight and overweight $(\mathrm{P}<0.001)$. Participants who had an inaccurate perception of their body shape had a higher significant correlation between being under-and/or overweight $(\mathrm{P}<0.001)$. The results showed that social media use did not correlate with underweight, while it correlated significantly with overweight $(\mathrm{P}=0.005)$.

\section{Eating disorders}

The mean score for the SCOFF test was $1.33 \pm 1.25$, with a minimum score of 0 and maximum of 5 . Of the 1,867 participants, 744

\begin{tabular}{|c|c|c|c|c|}
\hline $\begin{array}{l}\text { Demographic } \\
\text { Characteris- } \\
\text { tics }\end{array}$ & $\begin{array}{l}\text { Underweight } \\
(\mathrm{BMI}<18.5)\end{array}$ & P-Value & $\begin{array}{l}\text { Overweight } \\
\text { (BMI > 25) }\end{array}$ & P-Value \\
\hline $\begin{array}{l}\text { Do you have } \\
\text { a perception } \\
\text { of ideal body } \\
\text { shape? }\end{array}$ & & \multirow[t]{3}{*}{$<0.001^{*}$} & & \multirow[t]{3}{*}{0.302} \\
\hline Yes & $88(5.8 \%)$ & & $909(60.2 \%)$ & \\
\hline No & $42(11.7 \%)$ & & 205 (57.3\%) & \\
\hline $\begin{array}{l}\text { What is the } \\
\text { ideal body } \\
\text { shape, in your } \\
\text { opinion? }\end{array}$ & & \multirow{6}{*}{$<0.001^{*}$} & & \multirow{6}{*}{$<0.001^{*}$} \\
\hline Very Skinny & $5(35.7 \%)$ & & $2(14.3 \%)$ & \\
\hline Thin & $41(5.3 \%)$ & & $474(61.6 \%)$ & \\
\hline Buxom & $19(6.3 \%)$ & & $209(69.2 \%)$ & \\
\hline Muscly & 29 (7.5\%) & & $201(52.1 \%)$ & \\
\hline $\begin{array}{l}\text { There is } \\
\text { no specific } \\
\text { perfect body } \\
\text { shape }\end{array}$ & $36(9.1 \%)$ & & $228(57.7 \%)$ & \\
\hline
\end{tabular}

\begin{tabular}{|c|c|c|c|c|}
\hline \multicolumn{2}{|c|}{$\begin{array}{l}\text { How do you see your body } \\
\text { shape? }\end{array}$} & \multirow{6}{*}{$<0.001^{*}$} & & \multirow{6}{*}{$<0.001 *$} \\
\hline Very Skinny & $44(84.6 \%)$ & & $1(1.9 \%)$ & \\
\hline Thin & $71(19.6 \%)$ & & $39(10.7 \%)$ & \\
\hline Buxom & $3(0.3 \%)$ & & $703(77.9 \%)$ & \\
\hline Muscly & $4(6 \%)$ & & $25(37.3 \%)$ & \\
\hline $\begin{array}{l}\text { There is } \\
\text { no specific } \\
\text { perfect body } \\
\text { shape }\end{array}$ & $8(1.7 \%)$ & & $346(71.8 \%)$ & \\
\hline \multicolumn{5}{|c|}{$\begin{array}{l}\text { Do you spend time on social media platforms like Instagram, } \\
\text { TikTok, Snapchat, YouTube or Twitter? }\end{array}$} \\
\hline Yes & $103(7.5 \%)$ & \multirow{3}{*}{0.126} & $795(58 \%)$ & \multirow{3}{*}{$0.045^{*}$} \\
\hline No & $2(2.2 \%)$ & & $60(67.4 \%)$ & \\
\hline Sometimes & $25(6.1 \%)$ & & $259(63.5 \%)$ & \\
\hline \multicolumn{5}{|c|}{ If you use social media, how much do you use it every day? } \\
\hline Half an hour & $6(7 \%)$ & \multirow{6}{*}{0.089} & $60(69.8 \%)$ & \multirow{6}{*}{$0.005^{* *}$} \\
\hline An hour & $8(4 \%)$ & & $122(61.6 \%)$ & \\
\hline Two hours & $19(5.5 \%)$ & & 222 (64.7\%) & \\
\hline Three hours & $22(6.6 \%)$ & & 198 (59.1\%) & \\
\hline Four hours & $19(7.5 \%)$ & & 152 (59.8\%) & \\
\hline $\begin{array}{l}5 \text { hours or } \\
\text { more }\end{array}$ & $54(9.6 \%)$ & & 299 (53.3\%) & \\
\hline
\end{tabular}

Table 3: Factors Associated with Being Underweight/Overweight.

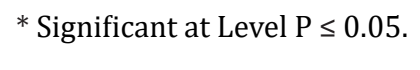

** Significant at Level $P \leq 0.005$.

(39.9\%) had a positive SCOFF score with at least two positive answers to the five questions. One thousand one hundred and twenty-three $(60.1 \%)$ participants gave normal SCOFF scores (a score of $<2$ ).

Table 4 demonstrates the relationship between EDs and several factors. A significant relationship has been noticed between EDs, age $(P=0.019)$, occupation $(P=0.001)$, having a health condition that requires treatment with medication $(\mathrm{P}=0.021)$, being a smoker $(\mathrm{P}<0.001)$, and spending time on social media $(\mathrm{P}<0.001)$.

\section{Stress and associated factors}

The mean score of the PSS was $22.90 \pm 4.2$ SD, with a minimum score of 0 and a maximum of 40 . A vast majority of $1,500(80.3 \%)$ 


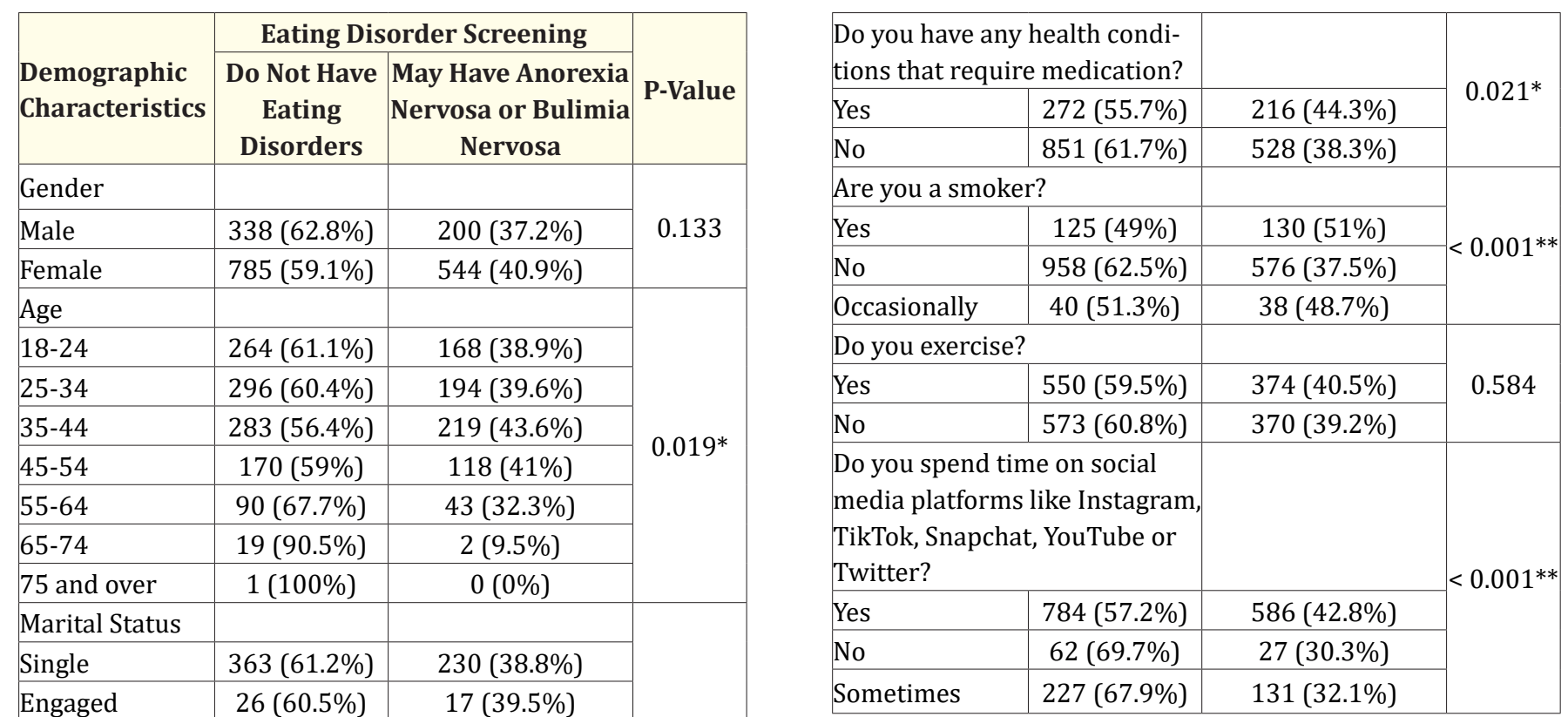

Table 4: Factors Associated with Eating Disorders.

$$
\begin{aligned}
& * \text { Significant at Level } \mathrm{P} \leq 0.05 \\
& * * \text { Significant at Level } \mathrm{P} \leq 0.005 .
\end{aligned}
$$

\begin{tabular}{|c|c|c|c|}
\hline Divorced & $55(56.1 \%)$ & $43(43.9 \%)$ & \\
\hline Separated & $10(71.4 \%)$ & $4(28.6 \%)$ & \\
\hline \multicolumn{3}{|l|}{ Qualification } & \multirow{7}{*}{0.322} \\
\hline None & $12(48 \%)$ & $13(52 \%)$ & \\
\hline High School & $205(58.6 \%)$ & $145(41.4 \%)$ & \\
\hline Diploma & 85 (58.6\%) & $60(41.4 \%)$ & \\
\hline Bachelor & $631(59.7 \%)$ & $426(40.3 \%)$ & \\
\hline Master & $120(64.5 \%)$ & $66(35.5 \%)$ & \\
\hline $\mathrm{PhD}$ & $70(67.3 \%)$ & $34(32.7 \%)$ & \\
\hline \multicolumn{3}{|l|}{ Job } & \multirow{12}{*}{$0.001^{*}$} \\
\hline $\begin{array}{l}\text { Work in public } \\
\text { sector }\end{array}$ & $332(60.8 \%)$ & $214(39.2 \%)$ & \\
\hline $\begin{array}{l}\text { Work in private } \\
\text { sector }\end{array}$ & $141(56 \%)$ & $111(44 \%)$ & \\
\hline Self-employed & $40(78.4 \%)$ & $11(21.6 \%)$ & \\
\hline $\begin{array}{l}\text { Not working and } \\
\text { looking for a job }\end{array}$ & $134(63.8 \%)$ & $76(36.2 \%)$ & \\
\hline $\begin{array}{l}\text { Not working and } \\
\text { not looking for } \\
\text { job }\end{array}$ & $25(40.3 \%)$ & 37 (59.7\%) & \\
\hline Housewife & $135(57.7 \%)$ & $99(42.3 \%)$ & \\
\hline Student & $197(59.2 \%)$ & $136(40.8 \%)$ & \\
\hline Military & $11(61.1 \%)$ & 7 (38.9\%) & \\
\hline Physician & $26(63.4 \%)$ & $15(36.6 \%)$ & \\
\hline Retired & $80(70.8 \%)$ & $33(29.2 \%)$ & \\
\hline Unable to work & $2(28.6 \%)$ & $5(71.4 \%)$ & \\
\hline
\end{tabular}

participants experienced moderate stress, 325 (17.4\%) experienced high stress, and 42 (2.2\%) experienced low stress.

Table 5 represents factors associated with stress. The following factors were found to correlate significantly with stress: working from home during the home confinement $(\mathrm{P}=0.004)$, having monthly income affected during the home confinement $(\mathrm{P}=0.004)$, and having a positive screening for EDs $(\mathrm{P}<0.001)$.

\section{Discussion}

To the best of our knowledge, this is the first study to screen for the incidence of EDs among citizens of Saudi Arabia during the COVID-19 quarantine. Comparable studies of EDs in the Middle East are limited and were all carried out before the COVID-19 pandemic [14-18]. These studies provide some limited insight into the prevalence of eating disorders in the Middle East before the pandemic, albeit in different populations.

The findings of the current research suggest a high possibility of $39.9 \%$ of developing eating disorders during the pandemic (see 


\begin{tabular}{|c|c|c|c|c|}
\hline \multirow{2}{*}{\begin{tabular}{|l|} 
Demographic \\
Characteristics
\end{tabular}} & \multicolumn{3}{|c|}{ Stress Level } & \multirow{2}{*}{ P-Value } \\
\hline & Low & Moderate & High & \\
\hline \multicolumn{4}{|l|}{$\begin{array}{l}\text { Underweight } \\
(\mathrm{BMI}<18.5)\end{array}$} & \multirow[b]{3}{*}{0.097} \\
\hline Yes & $4(3.1 \%)$ & 95 (73.1\%) & $31(23.8 \%)$ & \\
\hline No & $38(2.2 \%)$ & $1405(80.9 \%)$ & \begin{tabular}{c|c|}
294 \\
$(16.9 \%)$ \\
\end{tabular} & \\
\hline \multicolumn{4}{|l|}{$\begin{array}{l}\text { Overweight } \\
(\mathrm{BMI}>25)\end{array}$} & \multirow{3}{*}{0.611} \\
\hline Yes & $22(2 \%)$ & $896(80.4 \%)$ & $\begin{array}{c}196 \\
(17.6 \%)\end{array}$ & \\
\hline No & $20(2.7 \%)$ & $604(80.2 \%)$ & $\begin{array}{c}129 \\
(17.1 \%)\end{array}$ & \\
\hline \multicolumn{4}{|c|}{ Are you working from home during the quarantine? } & \multirow{4}{*}{$0.044^{*}$} \\
\hline Yes & $10(1.8 \%)$ & $424(76.8 \%)$ & $\begin{array}{c}118 \\
(21.4 \%)\end{array}$ & \\
\hline No & $24(2.3 \%)$ & $873(82 \%)$ & $\begin{array}{c}167 \\
(15.7 \%)\end{array}$ & \\
\hline Shifts & $8(3.2 \%)$ & $203(80.9 \%)$ & $40(15.9 \%)$ & \\
\hline \multicolumn{4}{|c|}{$\begin{array}{l}\text { Has your monthly income been affected because of the } \\
\text { quarantine? }\end{array}$} & \multirow{4}{*}{$0.004^{* *}$} \\
\hline Same & $21(1.7 \%)$ & $1044(82.1 \%)$ & $\begin{array}{c}206 \\
(16.2 \%)\end{array}$ & \\
\hline Less & $16(3.4 \%)$ & $367(78.3 \%)$ & $86(18.3 \%)$ & \\
\hline More & $5(3.9 \%)$ & $89(70.1 \%)$ & $33(26 \%)$ & \\
\hline \multicolumn{4}{|l|}{$\begin{array}{l}\text { Eating } \\
\text { Disorders } \\
\text { Screening } \\
\end{array}$} & \multirow{3}{*}{$\begin{array}{c}< \\
0.001^{* *}\end{array}$} \\
\hline $\begin{array}{l}\text { No eating } \\
\text { disorders }\end{array}$ & $33(2.9 \%)$ & 937 (83.4\%) & $\begin{array}{c}153 \\
(13.6 \%)\end{array}$ & \\
\hline $\begin{array}{l}\text { May have } \\
\text { anorexia } \\
\text { nervosa or } \\
\text { bulimia nervosa }\end{array}$ & $9(1.2 \%)$ & $563(75.7 \%)$ & $\begin{array}{c}172 \\
(23.1 \%)\end{array}$ & \\
\hline
\end{tabular}

Table 5: Factors Associated with Stress.

* Significant at $\mathrm{P}<0.05$.

** Significant at Level $\mathrm{P} \leq 0.005$.

Table 4), which support findings from recent similar studies in Lebanon, the United States and the Netherlands [19, 20]. The results show that EDs were associated with job or workplace among the participants of the present study. During the quarantine, many peo- ple lost their job, changed their workplace, assumed more duties and responsibilities, took on longer shifts or working hours or had lower income [21]. These factors result in elevated levels of stress. Job stress and a high level of competition to keep their jobs have been linked to the development of EDs [22]. Eating behaviours are influenced by workplace factors in the social, emotional and practical domains [22].

Stress was one of the most important predictors of EDs among the participants in the current study, as is expected under the circumstances of the pandemic. Many participants indicated that they experienced moderate to high levels of stress increases during the COVID-19 pandemic. These results are in line with previous studies that have shown increases in symptoms of depression, anxiety and loneliness in the general population during the current public health crisis [23]. The percentage of our participants who reported being moderately stressed $(80.3 \%)$ or severely stressed $(17.4 \%)$ according to the perceived stress scale is consistent with findings from studies carried out in Saudi Arabia, Spain and China that evaluated mental health issues during the COVID-19 pandemic [24-26].

Our results reveal a significant positive correlation between stress and working from home during the home confinement period, which is in line with the findings of recent studies that have linked stress during the pandemic to the overlap of work and family life, as working from home requires employees to remain productive while balancing domestic responsibilities [27].

An interesting finding from our study was the relationship of EDs to both baseline levels of family income and changes to it during the pandemic. Our study also shows that respondents whose monthly household income was affected because of the home confinement suffered increased stress that may heighten the risk of EDs. These findings might indicate that people with higher socioeconomic status (SES) maintain healthier dietary habits due to increased access to healthcare services, weight loss activities, health clubs and access to healthier foods [28]. A study carried out in two major German cities also found that SES was positively correlated with the recognition of depression and eating disorders. Thus, these findings indicate that individuals with low education, low income and low-status occupations know less about the symptoms and prevalence of depression and EDs [29]. This runs counter to the study report that posits that respondents with incomes above 
the median were likely to have higher levels of symptomatic EDs than those below the median [29]. Future research should look to investigate the effect of income in Saudi Arabia in greater detail in order to determine the mechanisms through which socio-economic status influences ED symptomatology.

In our study, there was found to be a significant positive correlation between smoking and EDs. Smoking was highly prevalent among participants who had a higher vulnerability to developing EDs, which agrees with previous studies that have found that almost half of being eating disorder smoked, and almost $40 \%$ of BN patients and $30 \%$ of people with AN smoked [30].

Furthermore, this study also showed that use of social media platforms like Instagram, TikTok, Snapchat, YouTube and Twitter tended to be quite high in the overweight participants. This may indicate that overweight people perceive a high degree of pressure from social media to be thinner in order to meet social expectations. Obese and overweight adults are at greater risk of depression and emotional distress [31]. One aspect that may lead to depression in obese or overweight individuals is exposure to unrealistic media related to body image dissatisfaction in adolescents and young adults. A direct link between BMI and the degree of pressure to be thinner experienced through the media may explain why higher BMI levels correlated with higher depressive symptoms when media pressure on the body image was considered to be higher [31]. Moreover, pressure from mass media can lead to strict eating attitudes among people [32].

In the media, obese people are often absent or ostracised in fictional formats; obese and overweight characters tend to be portrayed as unattractive, unpopular and unsuccessful [15,33]. Several studies in Western countries have demonstrated that obesity is associated with increased incidences of body dissatisfaction [15]. One of the most common external contributors to body dissatisfaction is the media, and more recently, social media [34,35]. These images often promote unrealistic, unobtainable projections of ideal body type that cannot be achieved in real life. Those who feel they fail to measure up in comparison with these images can experience intense body dissatisfaction that is damaging to their psychological and physical well-being [36].

Participants in this study reported thinking about their body shapes more often during the quarantine. Most of the participants
(80\%) have a particular perception about what constitutes the ideal body shape, while a large proportion of them viewed the ideal body shape as thin. This perception may make people more susceptible to EDs.

Our findings suggest that COVID-19-related stress and anxiety may shape body image outcomes under conditions of physical and social distancing [37]. In addition, increased consumption of social media due to social distancing measures could contribute to elevated exposure to harmful eating and appearance-related content that intensifies ED psychopathology [38]. Women and young people were more likely to experience changes in thoughts and behaviours, including finding it more difficult to regulate food consumption, being more preoccupied with food and having increasing concerns about appearance. Potential explanations for this include heightened levels of stress and anxiety resulting from increased caregiving responsibilities and exposure to increased weight stigma via public health and social media messaging regarding obesity and COVID-19 [39].

The present study highlights how perceptions about ideal body shape had an effect on underweight participants. In addition, according to our results, perceptions of ideal body shape had an effect on participants with a BMI lower than 18.5 and above 25. An association was also found between participant self-perceptions of their body shape and BMI in both groups (underweight and overweight). Body image is an important aspect of a person's selfperception and is linked to body dissatisfaction which frequently leads to the development of eating disorders [40]. Negative body image involves feelings of shame, anxiety and self-consciousness. People who experience high levels of body dissatisfaction feel that their bodies are flawed in comparison with others, and sufferers are more likely to suffer from feelings of depression, isolation, low self-esteem, and EDs. Research has highlighted that body dissatisfaction is the best-known contributor to the development of AN and $\mathrm{BN}[41]$.

Participants reported experiencing weight gain during the quarantine, which is in line with other studies that have also reported weight gain among participants during the home confinement [42]. Our data support previous findings showing that restrictions during the COVID-19 pandemic increased the number of main meals, frequency of cooking and snacking [42-44]. Weight gain was as- 
sociated with higher consumption of most foods, including meat, dairy, fast foods, and even fruit, vegetables and legumes [45].

The strengths of our study include the easy accessibility of the survey with IP restrictions to control access. Additionally, the presentative sample size were recruited from different regions and nationalities. Nonetheless, the study had several limitations. First, all participants were recruited via social media, resulting in the sample being biased toward those who have access to and are familiar with technology. Second, the bias of reporting weight and height by the participants.

There are several ways in which future research may expand upon the present study. There would be some advantage of expanding the time period for measuring symptom change to more accurately capture the often episodic nature of disordered eating symptoms. Longitudinal research is required to investigate the long-term effects of the pandemic on a population and would allow the comparison of data from the start of the lockdown with data from later time points. This would help identify the ongoing, and potentially evolving, impact of the pandemic on EDs as it progresses. Future research may also wish to include further quantitative analysis of the relationships between the facilitators (e.g. low perceived control) and barriers to EDs (e.g. high social support) behaviour during periods of lockdown.

\section{Conclusion}

To conclude, our findings suggest that domestic confinement leads to an increase in the risk of developing EDs as well as an increase in weight gain during the quarantine. The results show that EDs among participants were positively correlated with job or workplace. Stress was one of the most important predictors of EDs among participants, and there was a significant correlation between stress and working from home during the quarantine. A higher proportion of participants reported that their monthly income had been affected because of quarantine, which appears to have led to increased stress that may contribute to the development of EDs. Individuals with obesity were at increased risk of being affected psychologically by social media. In addition, there was a significant relationship between smoking and EDs. Policymakers in the health sector should attempt to mitigate these factors to minimise the effect of the pandemic on mental and physical health. More educational material about EDs and mindfulness techniques, either online or in-person, should be made available to the population in different languages.

\section{Conflict of Interest}

The researcher declare there is no conflict of interest.

\section{Bibliography}

1. Stice E., et al. "Prevalence, incidence, impairment, and course of the proposed DSM-5 eating disorder diagnoses in an 8-year prospective community study of young women". Journal of Abnormal Psychology 122.2 (2013): 445.

2. Association AP. "Diagnostic and statistical manual of mental disorders (DSM-5®)”. American Psychiatric Pub (2013).

3. Widiger TA. "Diagnostic and statistical manual of mental disorders". Oxford University Press (2000).

4. Fairburn CG., et al. "The natural course of bulimia nervosa and binge eating disorder in young women". Archives of General Psychiatry 57.7 (2000): 659-665.

5. Baenas I., et al. "COVID-19 and eating disorders during confinement: Analysis of factors associated with resilience and aggravation of symptoms". European Eating Disorders Review 28.6 (2020): 855-863.

6. Manasse SM., et al. "Are individuals with loss-of-control eating more prone to dietary lapse in behavioural weight loss treatment? An ecological momentary assessment study". European Eating Disorders Review 26.3 (2018): 259-264.

7. Masheb RM., et al. "Binge abstinence is associated with reduced energy intake after treatment in patients with binge eating disorder and obesity". Obesity 24.12 (2016): 24912496.

8. Cohen SB. "Media exposure and the subsequent effects on body dissatisfaction, disordered eating, and drive for thinness: A review of the current research". Mind Matters: The Wesleyan Journal of Psychology 1 (2006): 57-71.

9. Polivy J and CP Herman. "Causes of Eating Disorders". Annual Review of Psychology 53.1 (2002): 187-213.

10. Tiggemann M and AS Pickering. "Role of television in adolescent women's body dissatisfaction and drive for thinness". In- 
ternational Journal of Eating Disorders 20.2 (1996): 199-203.

11. Hardaway J., et al. "Integrated circuits and molecular components for stress and feeding: implications for eating disorders". Genes, Brain and Behavior 14.1 (2015): 85-97.

12. Brooks SK., et al. "The psychological impact of quarantine and how to reduce it: rapid review of the evidence". The Lancet (2020).

13. Rodgers RF., et al. "The impact of the COVID-19 pandemic on eating disorder risk and symptoms". International Journal of Eating Disorders (2020).

14. Musaiger AO., et al. "Risk of disordered eating attitudes among adolescents in seven Arab countries by gender and obesity: A cross-cultural study". Appetite 60 (2013): 162-167.

15. Musaiger AO and M Al-Mannai. "Association between exposure to media and body weight concern among female university students in five Arab countries: a preliminary cross-cultural study". Journal of Biosocial Science 46.2 (2014): 240-247.

16. Melisse B., et al. "Eating disorders in the Arab world: a literature review". Journal of Eating Disorders 8.1 (2020): 1-19.

17. Thomas J., et al. "Eating attitudes and body image concerns among female university students in the United Arab Emirates". Appetite 54.3 (2010): 595-598.

18. Zeeni N., et al. "Eating disorders in Lebanon: directions for public health action". Community Mental Health Journal 53.1 (2017): 117-125.

19. Haddad C., et al. "Association between eating behavior and quarantine/confinement stressors during the Coronavirus disease 2019 outbreak" (2020).

20. Termorshuizen JD., et al. "Early impact of COVID-19 on individuals with self-reported eating disorders: A survey of 1,000 individuals in the United States and the Netherlands". International Journal of Eating Disorders 53.11 (2020): 1780-1790.

21. OECD, D.P.O.a. "The impact of the COVID-19 pandemic on jobs and incomes in G20 economies" (2020).

22. Leung, S., et al. "Factors associated with healthy and unhealthy workplace eating behaviours in individuals with overweight/ obesity with and without binge eating disorder". Obesity Science and Practice 4.2 (2018): 109-118.

23. Ahmed MZ., et al. "Epidemic of COVID-19 in China and associated psychological problems". Asian Journal of Psychiatry 51 (2020): 102092.

24. Kar SK., et al. "Coping with Mental Health Challenges During COVID-19, in Coronavirus Disease 2019 (COVID-19): Epidemiology, Pathogenesis, Diagnosis, and Therapeutics". S.K. Saxena, Editor. Springer Singapore: Singapore (2020): 199-213.

25. Gao J., et al. "Mental health problems and social media exposure during COVID-19 outbreak". Plos one 15.4 (2020): e0231924.

26. Alkhamees AA., et al. "The psychological impact of COVID-19 pandemic on the general population of Saudi Arabia". Comprehensive Psychiatry 102 (2020): 152192.

27. Wolor CW., et al. "How to Manage Stress Experienced by Employees When Working from Home Due to the Covid-19 Virus Outbreak". International Journal of Advanced Scientific Technologies, Engineering and Management Sciences 29 (2020): 8359-8364.

28. Gibbons P. "The relationship between eating disorders and socioeconomic status: it's not what you think". Nutrition Noteworthy 4.1 (2001).

29. von dem Knesebeck O., et al. "Socioeconomic status and beliefs about depression, schizophrenia and eating disorders". Social Psychiatry and Psychiatric Epidemiology 48.5 (2013): 775-782.

30. Solmi M., et al. "The association between smoking prevalence and eating disorders: A systematic review and meta-analysis". Addiction 111.11 (2016): 1914-1922.

31. Jeffers AJ., et al. "BMI and depressive symptoms: The role of media pressures". Eating Behaviors 14.4 (2013): 468-471.

32. Musaiger AO and M Al-Mannai. "Role of obesity and media in body weight concern among female university students in $\mathrm{Ku}$ wait”. Eating Behaviors 14.2 (2013): 229-232.

33. Ferris JE. "Parallel discourses and "appropriate" bodies: Media constructions of anorexia and obesity in the cases of Tracey 
Gold and Carnie Wilson". Journal of Communication Inquiry 27.3 (2003): 256-273.

34. Griffiths S., et al. "The contribution of social media to body dissatisfaction, eating disorder symptoms, and anabolic steroid use among sexual minority men". Cyberpsychology, Behavior, and Social Networking 21.3 (2018): 149-156.

35. McLean SA and SJ Paxton. "Body image in the context of eating disorders”. Psychiatric Clinics 42.1 (2019): 145-156.

36. Perloff RM. “Social media effects on young women's body image concerns: Theoretical perspectives and an agenda for research". Sex Roles 71.11-12 (2014): 363-377.

37. Swami V., et al. "COVID-19-related stress and anxiety are associated with negative body image in adults from the United Kingdom". Personality and Individual Differences 170 (2021): 110426.

38. Robertson M., et al. "Exploring changes in body image, eating and exercise during the COVID-19 lockdown: A UK survey". Appetite 159 (2021): 105062.

39. Pearl RL. "Weight stigma and the "Quarantine-15". Obesity 28.7 (2020): 1180-1181.

40. Peat CM., et al. "Body image and eating disorders in older adults: a review". The Journal of General Psychology 135.4 (2008): 343-358.

41. Stice $\mathrm{E}$ and $\mathrm{K}$ Whitenton. "Risk factors for body dissatisfaction in adolescent girls: a longitudinal investigation". Developmental Psychology 38.5 (2002): 669.

42. Di Renzo L., et al. "Eating habits and lifestyle changes during COVID-19 lockdown: an Italian survey". Journal of Translational Medicine 18 (2020): 1-15.

43. Ammar A., et al. "Effects of COVID-19 home confinement on eating behaviour and physical activity: results of the ECLBCOVID19 international online survey". Nutrients 12.6 (2020): 1583.

44. Rodríguez-Pérez C., et al. "Changes in dietary behaviours during the COVID-19 outbreak confinement in the Spanish COVIDiet study". Nutrients 12.6 (2020): 1730.
45. Sidor A and P Rzymski. "Dietary choices and habits during COVID-19 lockdown: experience from Poland". Nutrients 12.6 (2020): 1657.

\section{Volume 5 Issue 10 October 2021}

(C) All rights are reserved by Khloud Ghafouri., et al. 